Bentham OPEN
CrossMark
Content list available at: www.benthamopen.com/TOORTHJ/
DOI: $10.2174 / 1874325001711010029$

RESEARCH ARTICLE

\title{
A Prospective Cohort Study of the Therapeutic Patterns, Challenges and Outcomes of Paediatric Femoral Fractures in a Cameroonian Tertiary Center
}

Joel Noutakdie Tochie ${ }^{1,2, *}$, Marc Leroy Guifo ${ }^{1,2}$, Marie-Ange Ngo Yamben ${ }^{1,3}$, Roger Moulion ${ }^{4}$ and Ibrahim Farikou, ${ }^{1,3}$

${ }^{I}$ Department of Surgery and Sub-specialties, Faculty of Medicine and Biomedical Sciences, University of Yaoundé 1, Yaoundé, Cameroon

${ }^{2}$ Department of Surgery, University Teaching Hospital of Yaoundé, Yaoundé, Cameroon

${ }^{3}$ Department of Orthopaedics and Traumatology, Yaoundé Rehabilitation Centre, Yaoundé, Cameroon

${ }^{4}$ Department of Radiology and Medical Imaging, University Teaching Hospital of Yaoundé, Yaoundé, Cameroon

Received: December 03, 2016

Revised: December 23, 2016

Accepted: December 29, 2016

Abstract:

\section{Background:}

Knowledge of the therapeutic patterns, challenges and outcomes of treatment of paediatric femoral fractures (PFF) helps to better choose the ideal therapeutic modality which is still controversial. However, this data is scarce in the sub-Saharan African literature.

\section{Objective:}

To determine the therapeutic patterns, treatment challenges and outcomes of treatment of PFF in a tertiary care centre in Cameroon.

\section{Method:}

We conducted a prospective cohort study of all consenting consecutive cases of femoral fractures in patients younger than 16 years managed between 2011 and 2015 at the surgical unit of Yaoundé University Teaching Hospital, Cameroon. We analysed demographic data, injury characteristics, fracture patterns, treatment details, therapeutic challenges and outcomes of treatment at 12 months using Flynn's criteria.

Results:

We enrolled 30 femoral fractures from 29 children with mean age was $4.2 \pm 3.3$ years. The male gender, diaphyseal locations and spiral fracture lines were predominant. Main mechanisms of injury were accidental falls, road traffic accidents and game injuries. Fracture management entailed 12 tractions followed by casting, 10 casting alone, four closed reductions followed by casting, two cannulated screw fixations, one pin fixation and one external fixation. The mean duration of consolidation was $10.3 \pm 3.9$ weeks. The outcome was rated excellent in 28 cases. Limited resources precluded fluoroscopy use, proper anaesthetic management, early rehabilitation and patient-parent satisfaction.

\section{Conclusion:}

Conservative management of PFF yields a good outcome in our setting. However, an improvement in surgical, radiology and anaesthetic infrastructure is needed for optimal PFF care.

Keywords: Femoral fractures, Paediatric, Treatment, Challenges, Outcomes, Cameroon.

* Address correspondence to this author at the University Teaching Hospital of Yaoundé, Yaoundé, P.O. Box 2666, Cameroon; Tel: +237 676558825; E-mail: joeltochie@gmail.com 


\section{INTRODUCTION}

Femoral fractures occur at a rate of 20 per 100,000 children in the USA, representing $1.6 \%$ of all paediatrics fractures [1], yet they inflict significant adverse physical, social, psychological, and financial impacts to both affected children and parents [2]. They are more common amongst males [1,3]. Their incidence is bimodal: first peaking between two and four years and later during adolescence [3, 4]. The aetiologies are often age-dependent and include traffic accidents, unintentional injuries (falls and games), child abuse and pathological states [3, 4].

There is still no consensus on the best method of managing paediatric femoral fractures, especially diaphyseal fractures. Evidence from a recent systematic review of randomized controlled trials did not ascertain the efficacy of conservative management over surgical management of femoral shaft fractures and vice versa, in terms of long-term functional outcome [5]. The choice between conservative and surgical treatment has traditionally been multifactorial, influenced by age and weight of the child, associated injuries, the fracture characteristics, institutional or surgeons' preferences, economic and social concerns [5 - 7]. Due to rapid bone remodelling, most of the femoral fractures in children younger than six years can be managed conservatively by traction and plaster-cast immobilization [8]. After six years of age, femoral shaft fractures in particular, managed non-operatively may be complicated by loss of reduction, mal-union and poor school attendance [3,8]. Thus, the best treatment option between 6 and 15 years of age is controversial [2, 8 - 10]. Over the last two decades, there has been a preference for surgical reduction of these fractures in children older than six years of age $[6,8]$. This preference stems from early mobilization, shorter hospital stay and avoidable detrimental psychological and financial losses experienced by patients and members of their families [2, 3, 8]. Moreover, the use of flexible intramedullary nailing has revolutionized the treatment of paediatric femoral fractures by improving on cost-effective results; early union due to repeated micro-motion at fracture site, respect for the physeal plates, early ambulation, minimal scaring, easy implant removal and tremendous patient satisfaction [8, 11]. However, this surgical option coupled with other invaluable health care infrastructures like fluoroscopy are still inexistent in many low-income countries, hindering efforts for current goal standard surgical reduction of paediatric femoral fractures [11]. Few studies have been published on paediatric femoral fractures in resource-constraint environments like the subSaharan African region [11, 12]. Hence, we proposed this study to determine the therapeutic patterns, treatment challenges and outcomes of the treatment of paediatric femoral fractures in the surgical unit of a tertiary center of Cameroon. The research goal is to provide some evidence which may guide clinicians make informed decisions in their choices of therapeutic strategies for paediatrics femoral fractures in resource-limited settings.

\section{MATERIALS AND METHODS}

We carried out a prospective cohort study of all cases of paediatric femoral fractures managed between 2011 and 2015 at the surgical unit of Yaoundé University Teaching Hospital, Cameroon. Patient inclusion criteria were an age younger than 16 years; treated for non-pathological femoral fractures and followed-up for a year in the aforementioned hospital; informed consent given by the patient, parents or guardians; adequate radiological documentation. Using a structured questionnaire, all consenting consecutive participants were recruited on admission, and then examined clinically and radiologically in less than 30 minutes. Treatment was surgical or non-surgical depending on the patient's age, weight, associated injuries, the location and pattern of the fracture, economic and social concerns. Variables studied were demographique parameters, mechanisms of injury, clinical and radiological findings confirmatory of femoral fracture, fracture classification by the AO system [13] or Salter Harris classification where appropriate, details of treatment adopted, duration of immobilization and length of hospital stay. Additionally, we studied therapeutic challenges pertaining to the availability and type of anaesthetic management, availability of an intra-operative fluoroscopy and financial constraints of parents or guardians. The outcome of treatment at 12 months of follow-up was evaluated by fracture consolidation time and the occurrence of complications such as compartment syndrome, cast contact dermatitis, bed sores, angular deformity, non-union, limb length discrepancy, infection, refracture, amyotrophy or knee ankylosis

All patients underwent periodic clinical and radiological evaluation at intervals of 2, 6, 8, 12 and 24 weeks, as necessary if there was angulation post initial fracture reduction or suspected malunion. For operative treatment, weight bearing was allowed when the construct was stable. Following non-operative management, weight bearing was allowed at cast removal. The outcome of treatment was assessed as excellent, good or bad using the Flynn's criteria [11] Table 1. 
Table 1. Flynn's criteria for assessment of treatment.

\begin{tabular}{|c|c|c|c|}
\hline Features & Excellent & Good & Poor \\
\hline Limb length discrepancy & $<1 \mathrm{~cm}$ & $<2 \mathrm{~cm}$ & $>2 \mathrm{~cm}$ \\
\hline Angulation in degree & $<5 \mathrm{~cm}$ & $5-10 \mathrm{~cm}$ & $>10 \mathrm{~cm}$ \\
\hline Pain & Absent & Absent & Present \\
\hline Complication & Absent & $\begin{array}{c}\text { Minor and } \\
\text { resolved }\end{array}$ & $\begin{array}{c}\text { Major complication } \\
\text { and/or lasting morbidity }\end{array}$ \\
\hline
\end{tabular}

The data obtained were entered into Epi info 3.5.1 statistical software. All the variables were distributed in the form of simple frequencies. Means of numerical variables were reported and the threshold for statistical significance set at 0.05. Patients loss of follow-up were excluded from the final analysis.

\section{RESULTS}

\section{General Characteristics of Participants and Fracture Details}

During the study period, we managed 30 femoral fractures from 29 children representing $20 \%$ of all paediatric fractures managed in our hospital. These were 18 males and 11 females with a sex ratio of 1.6. Their mean age was 4.2 \pm 3.3 years with a median of 3 years. Their ages ranged from 4 days to 13 years and the most represented age group was $0-5$ years $(76 \%)$. The mechanisms of injury were eleven $(38 \%)$ accidental falls, nine (31\%) road traffic accidents, seven (24\%) game injuries, and two (7\%) obstetrical injuries (Table 2). Four patients presented with associated injuries to the head and clavicule; humerus; tibia; soft tissues. All fractures were closed. The affected femoral bone segments in decreasing frequencies were; 23 diaphyseal, five proximal and two distal femoral segments.

\section{Therapeutic Patterns}

Twenty-one (72.4\%) fractures were managed within 24 hours of injury. The fracture line in diaphyseal fractures was spiral in $14(60.9 \%)$ cases, oblique in six (26.1\%) cases, transverse in two $(8.7 \%)$ cases and communited in one $(4.3 \%)$ case. Twenty six $(86.7 \%)$ fractures were managed by non-operative or conservative methods namely; 12 by traction followed by plaster cast immobilisation (Fig. 1), 10 by plaster cast immobilization alone (Fig. 2) and four by closed reduction followed by casting. Surgical fixations involved open reduction and cannulated screws fixation in two cases (Fig. 3), pin fixation in one case and one case of external fixation.
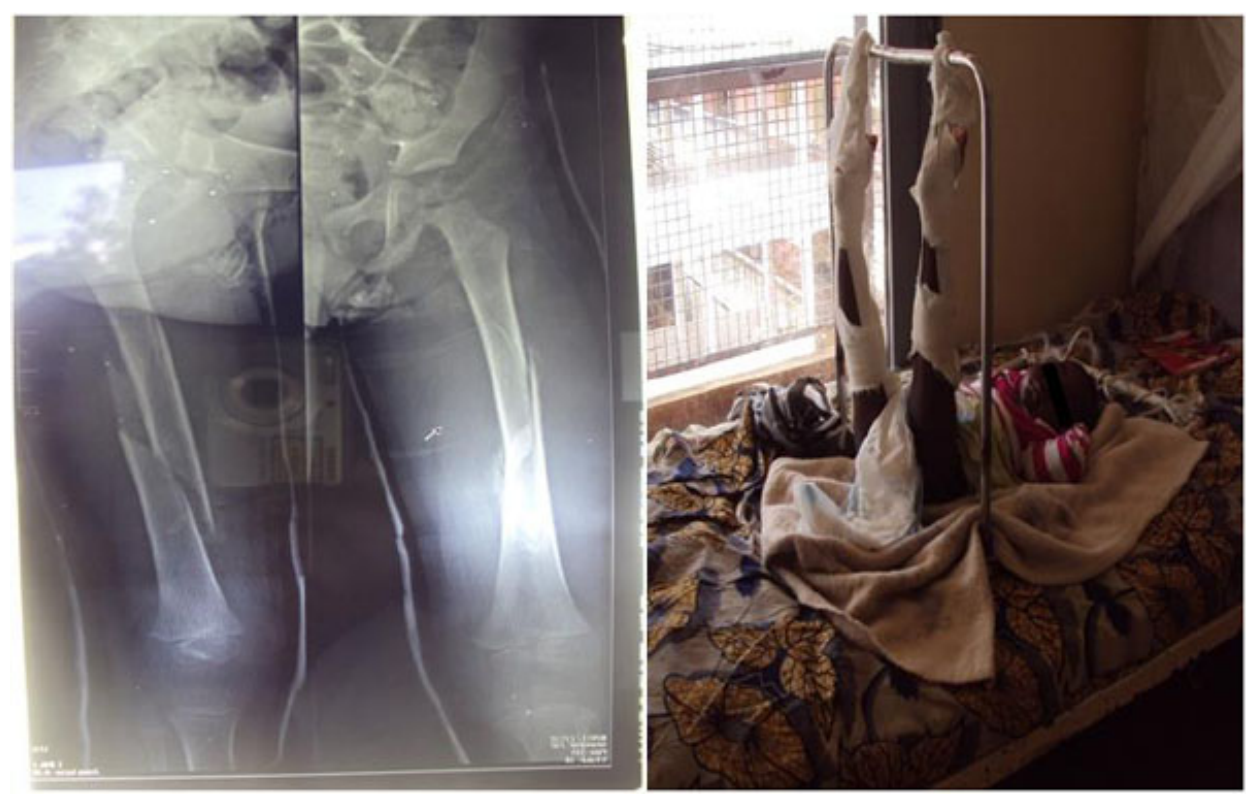

Fig. (1). Fractures of both femurs in a three-year old child managed by skin traction followed by casting. 


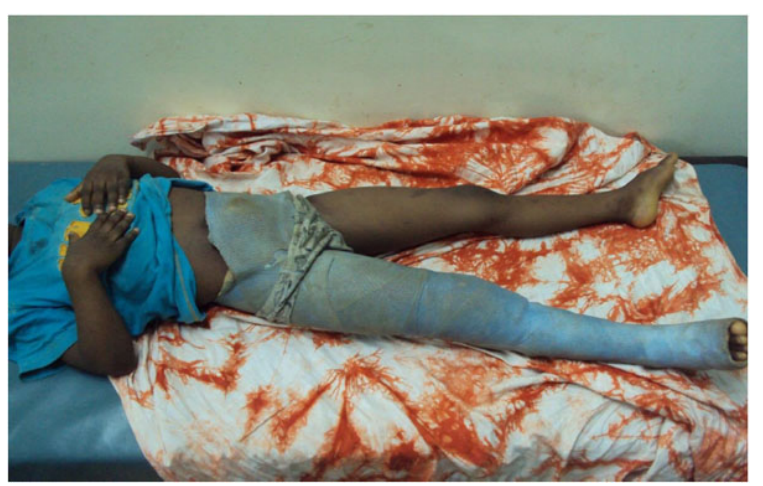

Fig. (2). A spiral femoral shaft fracture managed by a single-leg spica cast in a five-year old child.

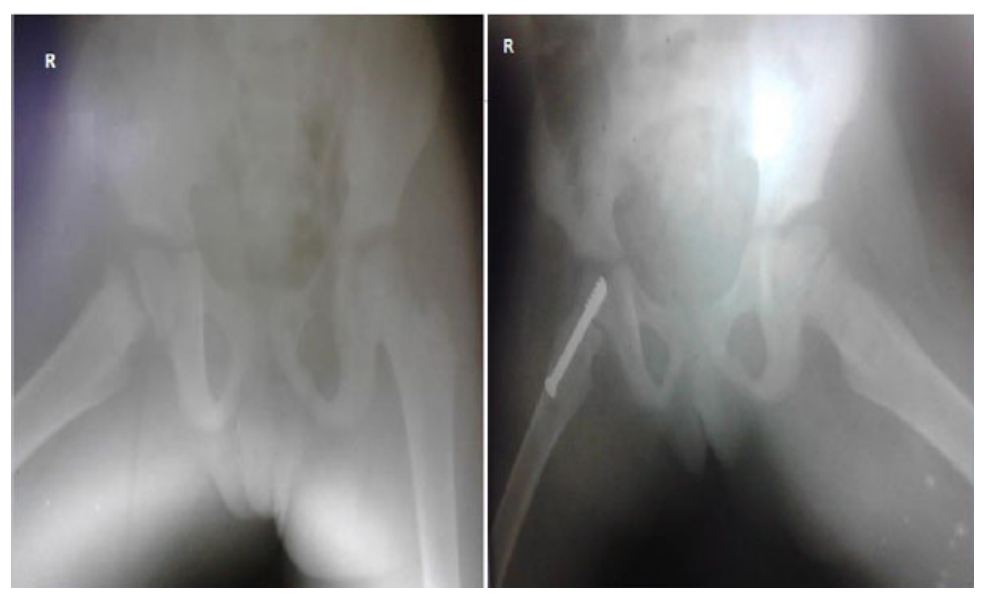

Fig. (3). Delbet type I fracture (right) in an 8-year-old girl treated by cannulated screw fixation (left).

Table 2. Characteristics of paediatric femoral fractures managed.

\begin{tabular}{|c|c|c|c|c|c|c|c|c|c|}
\hline Case & Age & $\operatorname{Sex}$ & $\begin{array}{c}\text { Mechanism of } \\
\text { injury }\end{array}$ & $\begin{array}{l}\text { AO } \\
\text { class }\end{array}$ & $\begin{array}{r}\begin{array}{r}\text { Other } \\
\text { injuries }\end{array} \\
\end{array}$ & Mode of treatment & $\begin{array}{c}\text { Type of } \\
\text { anaesthesia }\end{array}$ & Complication & Outcome \\
\hline 1 & 5 years & $\mathrm{M}$ & Game & 3.2.A.1.2 & None & conservative & None & None & Excellent \\
\hline 2 & 2 years & $\mathrm{M}$ & Fall & 3.2.A.1.2 & None & conservative & None & None & Excellent \\
\hline 3 & 3 years & $\mathrm{M}$ & Fall & 3.3.A.1.1 & None & conservative & None & None & Excellent \\
\hline 4 & \begin{tabular}{|c|}
22 \\
months
\end{tabular} & $\mathrm{M}$ & Game & 3.2.A.2.2 & None & conservative & None & None & Excellent \\
\hline 5 & 3 years & $\mathrm{M}$ & Fall & 3.2.A.1.3 & None & conservative & None & None & Excellent \\
\hline 6 & 5 years & $\mathrm{M}$ & RTA & 3.2.A.1.2 & Humerus & conservative & GA & None & Excellent \\
\hline 7 & 3 years & $\mathrm{F}$ & Fall & 3.2.A.1.2 & None & conservative & GA & None & Excellent \\
\hline 8 & 4 years & $\mathrm{M}$ & Game & 3.2.A.1.1 & None & conservative & None & None & Excellent \\
\hline 9 & 3 years & $\mathrm{M}$ & Game & 3.2.A.1.1 & None & conservative & None & None & Excellent \\
\hline 10 & \begin{tabular}{|c|}
11 \\
months \\
\end{tabular} & $\mathrm{F}$ & RTA & 3.2.A.1.2 & None & conservative & None & None & Excellent \\
\hline 11 & 4 days & $\mathrm{M}$ & Birth injury & 3.2.A.1.2 & None & conservative & None & None & Excellent \\
\hline 12 & 2 years & $\mathrm{F}$ & Fall & 3.2.A.2.1 & None & conservative & None & None & Excellent \\
\hline 13 & $\begin{array}{c}12 \\
\text { years }\end{array}$ & $\mathrm{M}$ & RTA & 3.2.A.2.1 & None & conservative & None & None & Excellent \\
\hline 14 & 8 years & $\mathrm{F}$ & Fall & 3.1.A.1.2 & None & conservative & None & None & Excellent \\
\hline 15 & 8 years & $\mathrm{M}$ & RTA & 3.1.A.2.1 & $\begin{array}{c}\text { Head + } \\
\text { Clavicle }\end{array}$ & conservative & None & None & Excellent \\
\hline 16 & \begin{tabular}{|c|}
3 \\
months \\
\end{tabular} & $\mathrm{F}$ & Fall & 3.2.A.2.2 & None & conservative & None & None & Excellent \\
\hline 17 & \begin{tabular}{|c|}
15 \\
months
\end{tabular} & $\mathrm{M}$ & RTA & 3.3.A.2.2 & None & conservative & None & None & Excellent \\
\hline
\end{tabular}




\begin{tabular}{|c|c|c|c|c|c|c|c|c|c|}
\hline Case & Age & $\operatorname{Sex}$ & $\begin{array}{l}\text { Mechanism of } \\
\text { injury }\end{array}$ & $\begin{array}{c}\text { AO } \\
\text { class }\end{array}$ & $\begin{array}{l}\text { Other } \\
\text { injuries }\end{array}$ & Mode of treatment & $\begin{array}{c}\text { Type of } \\
\text { anaesthesia }\end{array}$ & Complication & Outcome \\
\hline 18 & 6 years & $\mathrm{F}$ & Game & 3.2.A.1.2 & Tibia & conservative & None & $\begin{array}{c}\text { Angular Deformity }+ \\
\text { Malunion }\end{array}$ & Poor \\
\hline 19 & 2 years & $\mathrm{M}$ & Fall & 3.2.A.1.2 & None & conservative & None & None & Excellent \\
\hline 20 & 2 years & $\mathrm{M}$ & Game & 3.2.A.2.2 & None & conservative & None & None & Excellent \\
\hline 21 & 3 years & $\mathrm{M}$ & Fall & 3.2.A.1.2 & None & conservative & None & None & Excellent \\
\hline $21 \mathrm{bis}$ & 3 years & $\mathrm{M}$ & Fall & 3.2.A.1.2 & None & conservative & None & None & Excellent \\
\hline 22 & $\begin{array}{r}13 \\
\text { days }\end{array}$ & $\mathrm{M}$ & Birth injury & 3.2.A.2.2 & None & conservative & None & None & Excellent \\
\hline 23 & 3 years & $\mathrm{M}$ & RTA & 3.2.A.1.2 & None & conservative & None & None & Excellent \\
\hline 24 & 8 years & $\mathrm{F}$ & RTA & 3.2.C.1.2 & Soft Tissues & OREF & GA & $\begin{array}{l}\text { Limb Length } \\
\text { Discrepancy }\end{array}$ & Good \\
\hline 25 & $\begin{array}{c}13 \\
\text { years }\end{array}$ & $\mathrm{F}$ & RTA & 3.1.A.3.2 & None & ORIF $^{b}$ & GA & None & Excellent \\
\hline 26 & 5 years & $\mathrm{F}$ & Game & 3.1.A.1.1 & None & ORIF $^{\mathrm{b}}$ & GA & None & Excellent \\
\hline 27 & 5 years & $\mathrm{F}$ & Fall & 3.2.A.3.1 & None & conservative & None & None & Excellent \\
\hline 28 & 3 years & $\mathrm{M}$ & Fall & 3.2.A.2.2 & None & conservative & None & None & Excellent \\
\hline 29 & 8 years & $F$ & RTA & Salter Harris I & None & ORIF $^{a}$ & GA & None & Excellent \\
\hline
\end{tabular}

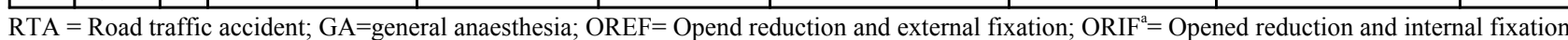
with cannulated screws; $\mathrm{ORIF}^{\mathrm{b}}=$ Opened reduction and internal fixation with pins.

\section{Therapeutic Challenges}

Therapeutic difficulties encountered during orthopaedic reductions were lack of sedation anaesthesia for all the 12 traction procedures and 8 out of the 10 closed reduction procedures, and unsatisfied parents by prolonged periods of immobilization of their kids. Therapeutic difficulties encountered during surgical reductions were: lack of an image intensifier fluoroscopy to cross-check anatomical re-alignment of fractures and financial constraints of parents which compelled the conversion of three surgical indications to non-operative management.

\section{Outcome of Treatment}

The mean duration of radiologic consolidation was $10.3 \pm 3.9$ weeks (range 5 - 23 weeks). Using Flynn's criteria, the outcome of treatment was rated excellent in 28 (93.3\%) cases, good in one (3.4\%) and poor in one (3.4\%) case. The "poor" outcome was an angular deformity of $12 \mathrm{~cm}$ with mal-union and residual pain at 12 months following skeletal traction a femoral shaft fracture in a 13 year old adolescent with financial constraints. The other complication was a limb length discrepancy of $1.5 \mathrm{~cm}$ following external fixation of a communited femoral fracture, assessed as a "good" outcome using Flynn's criteria (Fig. 4). We did not observe any case of compartment syndrome, non-union, rotational deformity, infection, refracture, amyotrophic or knee ankylosis. Children managed by conservative methods had longer durations of hospitalization, fracture immobilization and consolidation compared to those managed by surgery, though statistically insignificant (Table 3$)$. Longer immobilizations $(p<0.0001)$ and consolidation time $(p<0.0001)$ was observed in school age children (older than 5 years) compared to preschool children (younger than 6 years old) (Table 4).

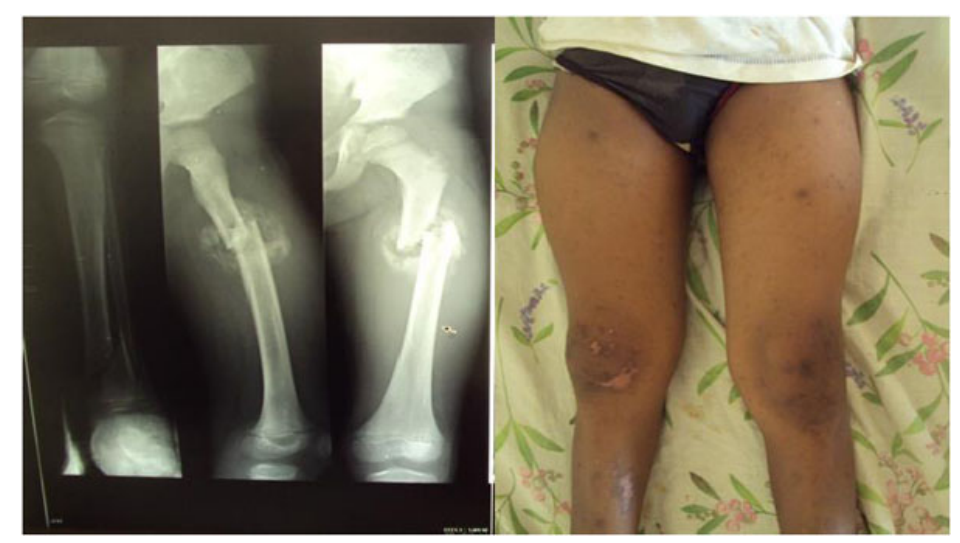

Fig. (4). Angular deformity and mal-union following management by skeletal traction for an oblique laterally displaced proximal diaphyseal femoral fracture (with an associated distal tibial fracture) in a 13-year old child with financial constraints.. 
Table 3. Comparison of conservative and surgical treatment.

\begin{tabular}{|c|c|c|}
\hline Variables & $\begin{array}{c}\text { Non operative } \\
\text { treatment } \mathbf{N}=\mathbf{2 6}\end{array}$ & $\begin{array}{c}\text { Operative value } \\
\text { Treatment N=4 }\end{array}$ \\
\hline Means of Length of hospital stay (weeks) & $3.0 \pm 1.1$ & $2.7 \pm 1.2$ \\
\hline Means of immobilization (weeks) & $7.8 \pm 3.4$ & 0.6191 \\
\hline Means of consolidation (weeks) & $10.4 \pm 4.2$ & 0.7799 \\
\hline
\end{tabular}

Table 4. Comparison of conservative treatment by age groups amongst the 23 cases.

\begin{tabular}{|c|c|c|c|}
\hline Variables & $\begin{array}{c}\mathbf{0 - 5} \text { years } \\
\mathbf{N}=\mathbf{2 3}\end{array}$ & $\begin{array}{c}\mathbf{6 - 1 5} \text { years } \\
\mathbf{N = 7}\end{array}$ & p value \\
\hline Means of Length of hospital stay (weeks) & $3.0 \pm .1 .2$ & $3.0 \pm .0 .7$ & 1.000 \\
\hline Means of immobilization (weeks) & $6.9 \pm 2.8$ & $12.3 \pm 1.1$ & $<\mathbf{0 . 0 0 0 1}$ \\
\hline Means of consolidation (weeks) & $9.3 \pm 3.0$ & $15.8 \pm 2.5$ & $<\mathbf{0 . 0 0 0 1}$ \\
\hline
\end{tabular}

\section{DISCUSSION}

Femoral fractures account for $20 \%$ of paediatrics fractures admitted in our surgical department. From the current literature, they represent less than $2 \%$ of fractures in children [1]. This may be explained by the fact that other types of paediatric fractures are less disabling in nature than femoral fractures, thus, often considered benign by the child's parents who tend to consult more traditional healers than health care centers for fracture management in our settings. Also, under-estimation of the true incidence of paediatric femoral fractures by the current literature also seems likely. These fractures pose a significant public health problem in low-income countries like Cameroon with increasing transport activities of commercial motor bikes, largely responsible for road traffic accidents in our cohort. Paediatric femoral fractures affect more boys (62.1\%) than girls (37.9\%), explained by the turbulent nature of boys and resultant high-risk play activities. This finding is consistent with that from other African series [12, 14, 15]. The mean age of children with femoral fractures was $4.2 \pm 3.3$ years and the most affected age group was $0-5$ years $(76 \%)$ explained by the fact this age group does not yet possess matured cognitive and perceptuo-motor abilities to avoid accidental injuries $[15,16]$. As such, their physical strength outweighs judgment, and protective reflexes are not fully developed making them a high risk group for femoral fractures [1]. This young mean age in our study may equally reflect the absence of parental awareness or education and the tendency of children to play at home or in in-secured playing grounds unsupervised. Other authors reported higher mean ages varying between due 6.8 - 7.5 years [3, 14].

The literature describes the mechanisms of injury of femoral fractures in children as age-dependent [1, 3, 4]. The main mechanisms in our series were unintentional injuries from falls $(38 \%)$ and games $(24 \%)$, consistent with our mean age of $4.2 \pm 3.3$ years and findings obtained in South Africa by Mughal et al. [15]. This is in contrast to other studies $[12,14,17]$ which reported road traffic accident as the major aetiology in $56.7-68.8 \%$ of cases, explained by their relative more active and older study population with a mean ages varying between 6.5 to 12.1 years.

There is no consistency regarding fracture line presentations from the literature $[1,3,4]$. We found $60.9 \%$ spiral, $26.1 \%$ oblique, $8.7 \%$ transverse and $4.3 \%$ communited fractures. Buechsenschuetz et al. found that $35.2 \%$ of the fractures were oblique, $35.2 \%$ transverse, $16.9 \%$ spiral and $12.6 \%$ comminuted [18].

Non-operative management was the mainstay of treatment in 26/30 cases and operative treatment in 4/30 cases. The indications of operative or non-operative management used in our series were similar to those described by several authors [6, 7]. In our study, the low mean age of participants $(4.2 \pm 3.3$ years), the low rate of associated injuries $(4 / 29$ children) and the high proportion of closed simple diaphyseal non displaced fractures (23/30 cases) were already highly suggestive that there should be greater indication of a conservative approach in fracture management. Although with low quality evidence, a recent meta-analysis of randomized controlled trials concluded that compared to conservative treatment, elastic intramedullary nailing may shorten rehabilitation time [5]. The benefits of a speed up recovery cannot be over emphasized, given our observed longer durations of immobilization $(p<0.0001)$ and consolidation $(p<0.0001)$ in school-aged children compared to preschool children. Using Flynn's criteria, the results of treatment were excellent in $25 / 26$ cases $(96.2 \%)$ managed by non-operative methods and excellent in 3/4 cases (75\%) managed operatively, with comparable durations of hospitalization, fracture immobilization and consolidation. This finding is of major economic significance in our resource-constrained setting where many parents cannot afford surgical management for their injured children. As reported by other African authors [11, 14, 17], we encountered infrastructural challenges from our 
health care setting as well as parental financial constraints which precluded optimal management of our patients. Measures which reduce hospital stay like home traction for toddlers and a brief period of traction followed by casting may curb these therapeutic challenges. Also, means for elastic intramedullary nailing and image intensifier fluoroscopy, should be put at the disposal of centers managing these fractures. While implementation of a national health insurance may ensure that injured children are being given the appropriate timely treatment and help resolve parental financial constraints.

We acknowledge some drawbacks of our study; its small sample size $(n=30)$ and single study setting. As such, our findings may be generalized to the entire nation with caution. However, based on well followed-up patients, we have used a cohort design to provide a contribution of level II scientific evidence to the scarcity of data on the treatment, challenges and outcomes of paediatric femoral fractures in the sub-Saharan African region. These findings may guide clinicians making informed decisions in their therapeutic strategies for paediatrics femoral fractures in resourcechallenged environments.

\section{CONCLUSION}

Our findings suggest that one out of every five paediatrics fractures encountered at our surgical department, are femoral fractures. Affected children are often younger than six years and boys are more affected than girls. Parents need to be sensitized on preventable aetiologies so as to be more vigilant. The treatment of these fractures by conservative methods yields favourable outcomes. This is of great economic interest in our resource-limited setting. However, modern evidence-based surgical techniques like elastic intramedullary nailing are needed for early rehabilitation, a better patient-parent satisfaction and prevent poor school attendance of injured school-aged children. Good quality multi-center randomized controlled trials comparing conservative versus surgical interventions for treating paediatric femoral fractures in sub-Saharan Africa are needed.

\section{LIST OF ABBREVIATIONS}

$\begin{array}{lll}\text { AO } & = & \text { Arbeitsgemeineschaft fur Osteosynthesefragen } \\ \text { PFF } & = & \text { Paediatric femoral fracture }\end{array}$

\section{CONFLICT OF INTEREST}

The authors confirm that this article content has no conflict of interest.

\section{ACKNOWLEDGEMENTS}

We sincerely thank the entire staff of the surgical unit of the University Teaching Hospital for their hospitality and commitment in ensuring a smooth run of the study.

\section{REFERENCES}

[1] Hinton RY, Lincoln A, Crockett MM, Sponseller P, Smith G. Fractures of the femoral shaft in children. Incidence, mechanisms, and sociodemographic risk factors. J Bone Joint Surg Am 1999; 81(4): 500-9. [PMID: 10225795]. [http://dx.doi.org/10.2106/00004623-199904000-00007] [PMID: 10225795]

[2] Sela Y, Hershkovich O, Sher-Lurie N, Schindler A, Givon U. Pediatric femoral shaft fractures: treatment strategies according to age13 years of experience in one medical center. J Orthop Surg 2013; 8: 23. [http://dx.doi.org/10.1186/1749-799X-8-23] [PMID: 23866728]

[3] Hoffmann CR, Traldi EF, Posser A. Epidemiological study of children diaphyseal femoral fractures. Rev Bras Ortop Engl Ed 2012; 47(2): $186-90$.

[http://dx.doi.org/10.1590/S0102-36162012000200007]

[4] Brown D, Fisher E. Femur fractures in infants and young children. Am J Public Health 2004; 94(4): 558-60. [http://dx.doi.org/10.2105/AJPH.94.4.558] [PMID: 15054003]

[5] Madhuri V, Dutt V, Gahukamble AD, Tharyan P. Interventions for treating femoral shaft fractures in children and adolescents. Cochrane Database Syst Rev 2014; 7(7): CD009076.

[http://dx.doi.org/10.1002/14651858.CD009076.pub2] [PMID: 25072888]

[6] Kosuge D, Barry M. Changing trends in the management of childrens fractures. Bone Joint J 2015; 97-B(4): 442-8. [http://dx.doi.org/10.1302/0301-620X.97B4.34723] [PMID: 25820880]

[7] Bassett WP, Safier S, Herman MJ, Kozin SH, Abzug JM. Complications of pediatric femoral shaft and distal physeal fractures. Instr Course Lect 2015; 64: 461-70.

[PMID: 25745929] 
[8] Saikia K, Bhuyan S, Bhattacharya T, Saikia S. Titanium elastic nailing in femoral diaphyseal fractures of children in 616 years of age. Indian J Orthop 2007; 41(4): 381-5. [http://dx.doi.org/10.4103/0019-5413.33876] [PMID: 21139795]

[9] Kumar S, Anand T, Singh S. Comparative study using intramedullary K-wire fixation over titanium elastic nail in paediatric shaft femur fractures. J Clin Diagn Res 2014; 8(11): LC08-10. [http://dx.doi.org/10.7860/JCDR/2014/9687.5119] [PMID: 25584251]

[10] Beaty JH. Operative treatment of femoral shaft fractures in children and adolescents. Clin Orthop Relat Res 2005; (434): 114-22. [PMID: 15864040].

[http://dx.doi.org/10.1097/01.blo.0000163463.05141.1c] [PMID: 15864040]

[11] Yaokreh JB, Odéhouri-Koudou TH, Koffi KM, et al. Surgical treatment of femoral diaphyseal fractures in children using elastic stable intramedullary nailing by open reduction at Yopougon Teaching Hospital. Orthop Traumatol Surg Res 2015; 101(5): 589-92. [http://dx.doi.org/10.1016/j.otsr.2015.05.006] [PMID: 26215090]

[12] Onche I, Igo A. Femoral shaft fractures: management and outcome in nigerian children. Afr J Paediatr Surg 2007; 4(1): 33-6.

[13] Wolinsky P, Stephen DJ. Femur, diáfise. In: Rüedi TP, Buckley RE, Eds. Princípios AO do tratamento de fraturas. Porto Alegre: Artmed 2009; pp. 849-67.

[14] Coulibaly Y, Keita M, Keita S, Traore M, Coulibaly T. Etude epidemio-Clinique et therapeutique des fractures du femur chezl'enfant. Mali Med 2009.

[15] Mughal MA, Dix-Peek SI, Hoffman EB. The epidemiology of femur shaft fractures in children. SA Orthopaedic Journal $2013 ; 12(4)$ : 23-7.

[16] Demetre JD. Applying developmental psychology to children's road safety: Problems and prospects. J Appl Dev Psychol 1997; 18: 263-70. [http://dx.doi.org/10.1016/S0193-3973(97)90040-X]

[17] Akinyoola AL, Orekha OO, Taiwo FO, Odunsi AO. Outcome of non-operative management of femoral shaft fractures in children. Afr J Paediatr Surg 2011; 8(1): 34-9. [http://dx.doi.org/10.4103/0189-6725.78666] [PMID: 21478584]

[18] Buechsenschuetz KE, Mehlman CT, Shaw KJ, Crawford AH, Immerman EB. Femoral shaft fractures in children: traction and casting versus elastic stable intramedullary nailing. J Trauma 2002; 53(5): 914-21. [http://dx.doi.org/10.1097/01.TA.0000026989.43823.5D] [PMID: 12435943]

(C) 2017 Tochie et al.

This is an open access article distributed under the terms of the Creative Commons Attribution 4.0 International Public License (CC-BY 4.0), a copy of which is available at: https://creativecommons.org/licenses/by/4.0/legalcode. This license permits unrestricted use, distribution, and reproduction in any medium, provided the original author and source are credited. 